\title{
14. Running the formula
}

\section{A POSITIVE AGENDA}

In this section, I introduce a positive agenda that would lead agencies to create comfort zones and to direct legal enforcements toward certain specific practices. The objective is to create the right incentives for blockchain communities to implement the "law is code" approach described in Chapter 13 - that is, translating the law into code in a way that opens up ex post enforcement. This approach would lead to a cooperative relationship between law and technology. The result would be better legal protection for blockchain communities (which would suffer from fewer anticompetitive practices) while ensuring blockchain creates a positive impact outside the ecosystem. ${ }^{1}$ But getting there will require mutual concessions.

\section{$1.1 \quad$ Comfort Zones}

\subsubsection{The legal side}

Agencies and regulatory bodies face the challenge of understanding blockchain code and programming. ${ }^{2}$ Without a comprehension of the ecosystem, most illegal activities on blockchain will remain undetected, creating a legal loophole and encouraging anticompetitive strategies using coding instead of contracts. ${ }^{3}$ This explains why former Assistant Attorney General Makan

1 See generally Tom R. Tyler, Why People Obey the Law (Yale University Press, 1990) (stating that people tend to obey the laws that they perceive as fair). Similarly, blockchain results from a desire for decentralization, and in this regard, the use of decentralized mechanisms by antitrust agencies could reinforce their acceptance.

2 Several antitrust agencies have started to learn about blockchain technicalities to meet future challenges, see, for instance, Makan Delrahim, "“Video Killed the Radio Star': Promoting a Culture of Innovation," the United States Department of Justice, October 8, 2020, https://perma.cc/T672-37A6. Also, Authority for Consumers \& Markets, "2018 ACM Conference," https://perma.cc/8MMU-EEXK.

3 This does not mean that antitrust and competition agencies must convict dozens of companies overnight based on the programming of their software. They must first gain expertise, notably by hiring software developers in their litigation teams. 
Delrahim stressed in a speech about blockchain that it is "vital for antitrust enforcers to understand how the emerging technology works." 4

I contend that the creation of comfort zones would be a great way for agencies to familiarize themselves with the ecosystem, whether they are innovation hubs (allowing firms to raise questions and seek clarifications and non-binding guidance), ${ }^{5}$ regulatory sandboxes (testing grounds for businesses supervised by regulatory bodies) ${ }^{6}$ or safe harbors (legal provisions exempting liability on the fulfillment of certain conditions, such as Section 230 of the Communication Act in the United States). ${ }^{7}$ These comfort zones would also allow agencies to test different modifications of blockchain code. This testing capacity would prove extremely beneficial for law enforcement. Initiatives such as the European Commission planning a pan-European blockchain regulatory sandbox that might become operational in 2022 are laudable in that respect. $^{8}$

But of course, most blockchains will not enter sandboxes for the sake of improving regulation: they must find it advantageous to do so. Being opt-in by nature, sandboxes require the creation of proper incentives. They could

4 Makan Delrahim, "Never Break the Chain: Pursuing Antifragility in Antitrust Enforcement," the United States Department of Justice, August 27, 2020, https://perma .cc/NEZ8-WC5E.

5 Regulatory Sandboxes and Innovation Hubs for FinTech: Impact on Innovation, Financial Stability and Supervisory Convergence, prepared by European Parliament (Brussels, 2020): 20 (underlining that "[i]nnovation hubs are often a compelling first step in the innovative regulatory journey;" indeed, "innovation hubs provide a platform to exchange knowledge and informal guidance, a regulatory sandbox usually implies some lenience or supervisory discretion about the way in which the regulatory framework applies to innovative products or services").

6 For instance, the Financial Conduct Authority is using sandboxes in the United Kingdom, see "The Financial Conduct Authority Unveils Successful Sandbox Firms on the Second Anniversary of Project Innovate," Financial Conduct Authority, November 7, 2016, https://perma.cc/3HQS-FBWS. See also Regulatory Sandboxes and Innovation Hubs for FinTech: Impact on Innovation, Financial Stability and Supervisory Convergence, prepared by European Parliament (Brussels, 2020): 21 (listing all the European countries with operational or planned sandboxes, such as Denmark, the Netherlands, Norway, Spain, Italy and Poland). Lastly, see Her Majesty's Treasury, "Ambitious plans to boost UK fintech and financial services set out by Chancellor," Gov.uk, April 19, 2021, https://perma.cc/K54K-GZLC (introducing the concept of "scale boxes" as a package of measures to enhance regulatory sandboxes and enable firms to test different products and services).

7 According to Section 230 of the Communications Act, online intermediaries are not liable for the content they display.

8 Regulatory Sandboxes and Experimentation Clauses as Tools for Better Regulation: Council Adopts Conclusions, prepared by General Secretariat of the Council of the European Union (Brussels, 2020), https://perma.cc/X5G2-WW93. 
be legal by nature. Typically, entities that enter comfort zones benefit from a flexible application of the law. They are sent "no enforcement action" letters in return for their collaboration and may ask agencies to help them assess the legality of grey practices. These firms may also benefit from having to comply with legal obligations tailored to their activities and therefore proportional to their business practices. Last, these incentives might be economic - for instance, in the form of tax breaks.

Ideally, regulators will enroll the blockchains (and related entities) that are expected to benefit society the most. Blockchains that are public, resilient to well-known attacks and free to use could be first to enter these comfort zones. Indeed, they offer optimum decentralization and lessen the risk of anticompetitive practices, as I have previously discussed in Part 2 of this book.

\subsubsection{The tech side}

On the tech side, opt-in sandboxes would increase developers' familiarity with legal mechanisms. ${ }^{9}$ They would also allow blockchain communities to enjoy related legal and economic advantages, plus to benefit from the rule of law. ${ }^{10}$ First, sandboxes would end up protecting them from anticompetitive practices, as they would implement relevant mechanisms to stop (most of) them. Though they might be tempted to try to achieve that objective with only code, this approach would fail. Code simply can't solve all problems on its own; blockchain needs the law.

Second, the law will provide blockchain participants with legal certainty and protection. This applies in the short and long term. In the short term, entering sandboxes provides legal certainty, as the dialogue with agencies and regulators is made easy. In the long term, sandboxes help the creation of well-defined legal systems. They help to shape legal rules to engage liability only in appropriate situations - here, when blockchain communities have control.

But of course, entering sandboxes would require developers to experiment with new blockchain designs that might make legal enforcement possible, fast and cost effective. One must distinguish between two possibilities in this regard. In the first, a public permissionless blockchain enters a sandbox at the stage of project development (before it hits the market). Here, experimentation is easy to implement, as core developers still have control over the blockchain. In the second, a public, permissionless blockchain that has already hit the

\footnotetext{
9 Which is not without creating a risk of regulatory capture. To remedy this, sandboxes results should be made open to all.

10 This is also true outside of antitrust law - for example, the Coin Center has applied for an exemption from the rules applying to money transmitters, see Peter Van Valkenburgh, "Bitcoin Innovators Need Legal Safe Harbors," Coin Center, January 24, 2017, https://perma.cc/774A-N7XB.
} 
market opts into a sandbox. Here, experimentation is more complicated, as developers will have already lost much of their control over design choices. Only the blockchain nucleus will have the power to implement them, constraining regulators to specific experiments.

Developers might also want to conduct experiments that alter different blockchain characteristics. For example, they could study whether a blockchain in which smart contracts can be stopped unilaterally by a handful of users would generate the same trust as unstoppable blockchains. ${ }^{11}$ They might also want to explore the impact of having a central entity collecting all real-life identities before allowing access to the blockchain. And one could imagine governance mechanisms that allow regulators to submit blockchain modifications to the community. ${ }^{12}$ These are just three examples of the need to assess which features can be modified without deteriorating blockchain differentiation (i.e., chances of survival) from centralized systems. ${ }^{13}$

The greater the effect of these modifications on the fundamental features of a blockchain, the more blockchain communities will be reluctant to implement them. To remedy that, the involvement of blockchain participants will be crucial. Regulators should thus determine what incentives should be granted for each mechanism. Eventually, the results of these experiments will be generalized to other blockchains - regulation could then leave the realm of sandboxes (which only concern a few) in favor of safe harbors (which apply to all).

\subsection{Enforcement}

\subsubsection{Not this...}

Enforcement is the second pillar of a collaborative approach between law and tech, antitrust and blockchain. I realize that this may seem counterintuitive; enforcement is, by definition, confrontational. In reality, distinct types of enforcement can lead to varying degrees of confrontation: some harm the entire blockchain, while others target the sole perpetrators of illegal practices. One should avoid the former, as it would reduce blockchain's usefulness and thus deprive policymakers and regulators of an important ally. It is in the interests of both communities to encourage the latter.

I concluded the first part of this book by underlining that making law and tech work toward the same objective implied bearing with some assaults by

11 See Aaron Wright and Primavera De Filippi, "Decentralized Blockchain Technology and the Rise of Lex Cryptographia" (2015): 50.

${ }_{12}$ These mechanisms could be similar to those of Decred, see Kevin Werbach, The Blockchain and the New Architecture of Trust (MIT Press, 2018): 549.

13 Proposing the introduction of a decentralized "supreme court," see Vitalik Buterin, "Decentralized Court," Reddit, https://perma.cc/K5CQ-URMK. 
each on the other. This means that blockchain communities should not only tolerate antitrust sanctions, but also facilitate them, because they ultimately lead to further decentralization. It also means that antitrust agencies and courts should direct their enforcement activities in a specific way. Overall, they should seek to preserve blockchain. This will be challenging, as agencies generally conduct their enforcement activities one case after the other, without such a long-term objective. That being said, agencies could still achieve the overall goal of enabling blockchain technology to flourish while ensuring case-by-case enforcement.

For that, agencies should avoid enforcement activities against practices that directly arise from the intrinsic characteristics of a blockchain. For example, public permissionless blockchains distribute information throughout the marketplace, including the number of transactions implemented by specific users, the fees being paid and so on. This transparency could lead to antitrust concerns, especially when it comes to tacit collusion. ${ }^{14}$ Nevertheless, because this essential feature makes markets more fluid and mitigates information asymmetry, ${ }^{15}$ enforcement activities should not be directed at it.

The same goes for the opacity that blockchains create. As we have seen together, the identity of a blockchain's participants and the content of their transactions are protected by encryption. Yet one should not consider this a relevant element in European competition law for presuming the intention to collude (moral component), for systematically making cartelization on blockchain a restriction "by object" rather than "by effect," or for easing the burden of proof on antitrust agencies. Doing so would deter legal uses of blockchain.

More generally, it is important to underline that all blockchain participants agree to the same set of rules. That should not be seen as an illegal agreement between them, even though it affects their economic behavior. Agreeing to the same rules is, in fact, necessary for blockchain's survival, as it creates consistency in the blockchain ledger in the absence of central coordination. It solves the Byzantine Generals Problem, according to which a central power is always needed to coordinate actions and maximize outcomes. That applies to forks, which should only rarely be seen as illegal (as I discussed in Chapter 8), because they create checks and balances within each blockchain. Let me reiterate that without consensus regarding the rules and their modification, the whole system would collapse, as the ledger integrity could not be maintained. All practices engaged by the blockchain nucleus to ensure survival, such as

14 See Lin William Cong and Zhiguo He, "Blockchain Disruption and Smart Contracts" (2017): 9 (underlining that decentralization facilitates collusion by distributing information).

${ }_{15} \quad I d$. at 3 
their forks and modifications of the core client, should thus be presumptively legal as far as antitrust enforcement is concerned.

\subsection{2 ...but that!}

I recommend that antitrust agencies focus their enforcement activities on practices that affect the "real space", and on practices that defeat blockchain's purpose.

As I discussed in Chapters 9 and 11, the first type of practice covers the use of blockchains to support firms' efforts to collude or monopolize markets. These practices have a strong and direct impact on consumers. Detecting this type of behavior will require proactive actions by antitrust agencies. If they engage in such actions, enforcement in the field will increase consumer welfare.

The second category concerns practices that centralize blockchain ecosystems artificially. More specifically, agencies should target practices that centralize the infrastructure level of a blockchain. As I have explained, that level has a critical influence on the decentralization of other levels. Prohibiting artificial forms of centralization at that layer will free most of the ecosystem from coercive forms of power. In doing so, it will make blockchain a more potent ally to antitrust law. Furthermore, this type of enforcement will prove increasingly important over time. If blockchain adoption continues to increase, it could very well become a key infrastructure for the world economy. At that point in time, the artificial centralization of blockchain will become antitrust agencies' top enforcement priority.

Overall, directing enforcement activities toward these two types of practices would free blockchain, and its economic ramifications, from the most restrictive practices without diminishing its usefulness or creating resentment within blockchain communities. Antitrust would thus become the ally of blockchain ecosystems and would start being perceived as such.

\section{REGULATION BY BLOCKCHAIN}

Up to this point, I have discussed an agenda for blockchain and antitrust to benefit from one another while staying in separate silos. In this section, I focus on how combining the two could strengthen their link on a long-lasting basis and lead to the emergence of a decentralized regulator. In a way, I propose a merger between law and technology. 


\subsection{Sketch of a Decentralized Regulator}

\subsubsection{The endgame}

Tensions between law and technology benefit neither of them. To remedy these frictions, the first part of this chapter put forward a proposal that would foster cooperation between them. But would it be possible to alleviate these tensions in a more sustainable way? The answer lies in the chosen methods of regulatory governance.

Absent a decentralization of antitrust agencies, the law is enforced top-down. It maintains a mistrust within blockchain communities and put the terms of their cooperation with regulators at risk. The decentralization of antitrust agencies could, on the contrary, bring the two spheres closer together. And as I shall explain, blockchain could allow for a more democratic and efficient decision-making. ${ }^{16}$

\subsubsection{Futarchic antitrust}

In what follows, I explain why and how antitrust agencies should use "futarchy" augmented by blockchain. But first, what is futarchy? To put it simply, futarchy is a system of governance based on the "wisdom of the crowd" which is using prediction markets - a way of making the future outcome of an event tradable. ${ }^{17}$

We know from the work of Friedrich Hayek that prices reflect the information distributed in the market. Prediction markets use this feature by putting a price on future outcomes in order to evaluate their likelihood. ${ }^{18}$ More specifically, they identify sincere beliefs ${ }^{19}$ by forcing participants to "put their money

16 See Marta Poblet et al., "From Athens to the Blockchain: Oracles for Digital Democracy" (2020); Melanie Swan, Blockchain: Blueprint for a New Economy (O'Reilly Media, 2015): 54 ("It might seem harder to let go of centralized authority in matters of government ... but there is no reason that social maturity could not develop in similar context").

17 Discussing other "wisdom of the crowd" technologies, see Robin Hanson, "Insider Trading and Prediction Markets" (2007) (they also include "wikis, blogs, collaborative filtering, link-popularity-based-search").

18 Robin Hanson, "Shall We Vote on Values, But Bet on Beliefs?" The Journal of Political Philosophy 21, no. 2 (2013): 5 ("Betting markets are speculative markets that trade assets that are specifically designed to allow people to bet on particular matters of fact, such as which horse will win a race"); also, Kenneth J. Arrow et al., "The Promise of Prediction Markets," Science 320, (2008): 877 (defining "prediction markets" as "forums for trading contracts that yield payments based on the outcome of uncertain events").

19 Robin Hanson, "Could Gambling Save Science? Encouraging an Honest Consensus," Social Epistemology 9, no. 1 (1995): 3, 7-9. Also, Michael Abramowicz, 
where their mouth is, ${ }^{20}$ and differ in this respect from traditional voting mechanisms that record what the voters want, as opposed to what they think will happen. ${ }^{21}$ These have been successfully applied in practice. ${ }^{22}$

In practice, one attributes the probability that a future event will occur between 0 and 1 , and creates a bet in which the entry price equals the perceived probability. After the event has (or has not) occurred, only those who bet on the correct outcome receive a payoff. Let me take an example. The likelihood that person $\mathrm{X}$ will be elected president of the United States is 70 percent. It follows that one will have to spend 0.7 (dollars, or euro, or tokens) to bet on person X's election. Conversely, one will have to put 0.3 to bet on person X's non-election. Once the result is known, the value corresponding to the correct result is converted into 1 . Here, if a participant has bet 0.7 dollars that person $\mathrm{X}$ would be elected, the bet is converted into 1 dollar, earning a payoff of 0.3 . Those who have bet against person $\mathrm{X}$ election lose their 0.3 dollars. This loss discourages bad gamblers from taking part in similar prediction markets (unless they enjoy losing money), which is why prediction markets are becoming more accurate over time. ${ }^{23}$

Now, let us focus on futarchy. Futarchy uses these bets to determine a governance strategy in the private and public sectors alike: participants bet on whether a specific outcome will occur after a specific decision is taken. One may distinguish between two distinct mechanisms.

In the first mechanism - the original form of futarchy introduced by Robin Hanson - two votes are submitted in parallel. Let us assume that the goal is to choose the best president for increasing a country's gross domestic product (GDP) one year after the election. Two bets are created regarding the odds that person $\mathrm{X}$ (one bet) and person $\mathrm{Y}$ (another bet) will reach that goal once

Predictocracy: Market Mechanisms for Public and Private Decision Making (Yale University Press, 2008): 7.

${ }^{20}$ Robin Hanson et al., "Decision Markets," IEEE Intelligent Systems 14, no. 3 (1999).

${ }^{21}$ If one wants to change the outcome, a prediction market is not the right tool.

22 See Frank M.A. Klingert and Matthias Meyer, "Comparing Prediction Market Mechanisms: An Experiment-Based and Micro Validated Multi-Agent Simulation," Journal of Artificial Societies and Social Simulation 21, no. 1 (2018); Also, Colin F. Camerer et al., "Evaluating Replicability of Laboratory Experiments in Economics," Science 351, no. 6280 (2016); Finally, see Pavel Atanasov et al., "Distilling the Wisdom of Crowds: Prediction Markets vs. Prediction Polls," Management Science 63, no. 3 (2016).

${ }^{23}$ Marti A. Hearst et al., "Building Intelligent Systems One E-Citizen at a Time," IEEE Intelligent Systems 14, no. 3 (1999): 16. 
elected president. They are both conditioned on the election, ${ }^{24}$ meaning that once a candidate is elected, the bet regarding the other candidate is automatically canceled and gamblers are refunded. Now, let us assume that the president-elect has achieved the goal of increasing the country's GDP at the end of the specified period (one year in this case). Those who had bet on her or his success see their values converted to 1 ; the others to 0 . In the second mechanism, a single bet is created ${ }^{25}$ - for instance, will person $\mathrm{X}$ increase the country's GDP one year after her or his election? If the bets are overwhelmingly positive, this indicates the desirability of electing that person. After a year, those who voted for the correct outcome earn a gain and the others take a loss. If person $\mathrm{X}$ is not elected, the bets are canceled.

That being cleared up, I realize that readers may still have a few interrogations regarding prediction markets and futarchies. For that reason, I shall address them in the form of questions and answers.

First, who creates these prediction markets? It can be a decision maker who is using them as a way to govern. For example, a company's shareholders could choose a CEO using a prediction market for evaluating the likelihood that she or he will increase the company's value. But in the original form of futarchy, the outcomes of the bets are simple indications that can be ignored. This enables non-decision makers to create prediction markets. In either case, futarchy allows for the decentralization of the decision-making process, enabling individuals with information to bet on outcomes and contributing their expertise to the decision. ${ }^{26}$

Second, who can bet? Three variants can be distinguished here. In the first, only specific participants can bet (e.g., members of a company or a governmental agency). This method gathers only limited expertise. In the second, specific participants and designated experts can submit bets, bringing external yet selective expertise to the process. In the third, bets are open to everyone. ${ }^{27}$

24 These markets are called "Conditional Prediction Markets," because they are contingent on some events, see Michael Abramowicz, Predictocracy: Market Mechanisms for Public and Private Decision Making (Yale University Press, 2008): 141.

25 See Justin Wolfers and Eric Zitzewitz, "Prediction Markets," Journal of Economic Perspectives 18, (2004): 107, 120 ("the new prediction markets in announcements of economic statistics operate more like the pari-mutuel systems that are common in horse-race betting. In a pari-mutuel system, all of the money that is bet goes into a common pot and is then divided among the winners after subtracting transaction costs").

${ }^{26}$ For one implementation, see Vitalik Buterin, "Prediction Markets for Content Curation DAOs," Ethereum Research, https://perma.cc/D22J-DNJK.

27 Tom W. Bell, "Government Prediction Markets: Why, Who, and How," Penn State Law Review 116, no. 2 (2011): 403, 416. 
This brings together broad expertise, but opens up a risk of manipulation I will come back to this.

Third, how do blockchain ecosystems fit within this picture? It appears that, regardless of its form, the benefits offered by futarchy are increased by blockchain. ${ }^{28}$ Blockchain provides transparency to the participants, which motivates fair behaviors. Blockchain is also censorship resistant, which allows for the creation of market predictions that cannot be altered or stopped by their creators. Once the result is registered, the funds are immediately transferred to those whose bet was correct, avoiding the lengths of centralized prediction markets where a financial institution must order the transfer. Conversely, those whose bets were incorrect cannot cheat - that is, the combination of cryptography and immutability forces voters to bear the costs and benefits of their bets.

In fact, blockchain also allows for mechanisms to be put in place to ensure that correct outcomes are being recorded. For example, several decentralized prediction markets are forcing the participants challenging an outcome (e.g., person X wasn't elected, person Y was) to place a financial stake that will be lost if they are proven wrong by the majority. ${ }^{29}$ This is the process used by Augur, a decentralized prediction market launched on the Ethereum blockchain. Augur enables the creation of prediction markets that work with a reputation token (called "Rep") where users are randomly chosen to verify outcomes. They win new tokens if they do the verification accurately. ${ }^{30}$

Lastly, blockchain allows the use of tokens instead of fiat currencies for betting purposes. ${ }^{31}$ The advantage of using fiat currencies is their immediate appeal to attract gamblers, thus increasing expertise. That being said, the use of tokens - which did not turn out to be leading to less accurate outcomes when they have been used ${ }^{32}$ - might still create proper financial incentives. Using

28 Melanie Swan, Blockchain: Blueprint for A New Economy (O'Reilly Media, 2015): 53 (describing prediction markets as "a quintessential example of the potential transformative power of blockchain technology").

29 Ben Davidow, "The Ultimate Guide to Decentralized Prediction Markets," Medium, August 22, 2019, https://perma.cc/3W7C-2BZN.

30 See Dr. Jack Peterson and Joseph Krug, "Augur: a Decentralized, Open-Source Platform for Prediction Markets" (2015); and, also, Pete Rizzo, "Augur Bets on Blockchain-Powered Prediction Markets," CoinDesk, March 1, 2015, https://perma .cc/SKV3-3C2T ("[a]fter the election happens, because there's not a centralized source that confirms that it's happened, there has to be a decentralized reporting system. That's where reputation comes in. Reputation holders are asked to report on the outcome of events and that ensures the integrity of the system").

31 One may see nonetheless a recent decline of prediction markets, see State of Adoption, "Report 2019/2020" (2020), https://perma.cc/PZA9-X92Y.

32 Emile Servan-Schreiber et al., "Prediction Markets: Does Money Matter?" Electronic Markets 14 (2004): 243 ("the play-money markets did not perform any worse than the real-money markets. We speculate that this result reflects two oppos- 
tokens also allows for the creation of betting markets in which reputation is at stake rather than financial gains. These tokens can indeed be public tokens such as Ether, but they can also be created for betting and used only within a firm or agency. They do not necessarily need to be convertible in fiat currencies or other tokens. A simple reputation system can suffice to create a strong incentive for participants to bet only when they possess inside information. Furthermore, using tokens instead of fiat currencies might allow the triggering of smart contracts.

\subsection{Decentralized Regulator in Action}

Thomas B. Leary, a former FTC commissioner, underlined in 2011 that "virtually all antitrust analysis involves predictions." ${ }^{33}$ In recent years, competition law has undergone radicalization in that regard. Two camps seem to have formed: the first extols markets' ability to correct failures, while the second argues for systematic governmental intervention to do so. Futarchy can help balance these two camps by forcing them to bet not on their beliefs or desires, but on what they expect to become reality. Futarchy will reward only those who are right, creating an incentive not to take a purely ideological stance. ${ }^{34}$ I take three examples: (1) merger control; (2) commitments and remedies; and (3) the design of competition policies. I explain that futarchy could benefit these three areas of antitrust law, whether they concern blockchain antitrust or not. In a sense, this section is about how blockchain could help regulators by allowing trustful futarchies.

\subsubsection{Merger control}

Futarchy can help improve merger control analysis in which antitrust agencies are tasked to address whether "the effect of [an] acquisition may be substantially to lessen competition or to tend to create a monopoly."

Let us assume a merger between two companies, $\mathrm{X}$ and $\mathrm{Y}$. The relevant antitrust agency creates two prediction markets to discover whether, one year after the merger, the average price of the product at stake has greater chances of increasing if the merger is authorized. The first assumes that the merger

ing forces: real-money markets may better motivate information discovery while play-money market may yield more efficient information aggregation").

33 Thomas B. Leary, "The Inevitability of Uncertainty," Competition Law International 3 (2007): 27. On this, see Albert A. Foer, "Prediction and Antitrust," The Antitrust Bulletin 56 (2011): 505.

34 Discussing the use of prediction markets to anticipate court outcomes, see Michael Abramowicz, Predictocracy: Market Mechanisms for Public and Private Decision Making (Yale University Press, 2008): 232. 
is accepted and the second that it is prohibited. After the betting period has expired, it presents the antitrust agency with two probabilities. One shows 80 percent of the gamblers betting that the price will increase over a certain value if the merger is accepted, and the other only 30 percent that it will reach the same value if the merger is prohibited. The agency could bind itself to these results, here prohibiting the merger. Evidently, companies and competitors will have a strong incentive to try gaming the bets; but again, should they succeed, and should the future prove them wrong, they will lose the money corresponding to their bets.

In fact, this mechanism could incentivize companies to recognize the possible effects of their merger on the market, rather than argue systematically that there are no competitive issues. As a result, they could propose commitments and submit them to the prediction market to influence it in their favor. For example, they could offer to divest part of their activities for influencing the bets or come up with behavioral remedies.

Once the period stated in the prediction market has elapsed (here, one year), the real-life outcome will be shown (the price has increased or not). Those who have bet on the right decision (the merger was allowed or prohibited) and the right outcome (the price has gone up or down) make a profit. Those who have bet on the right decision but the wrong outcome record a loss. And all those who have bet on the wrong decision get their money back.

Evidently, the company could maintain prices artificially low until the end of the period and raise them after it has expired. Should the period be lengthened in response, the prediction market could be less liquid, as the incentive to bet over a longer period will be diminished. However, one could create several prediction markets for different periods and make a decision (on allowing the merger or not) based on them all. In any event, a company raising prices right after the period embedded in prediction markets would severely jeopardize the likelihood of obtaining approvals without commitments in future cases.

So, who should vote? These bets could initially be submitted to the personnel of antitrust agencies alone. One could use an internal token for voting rights, the objective being to prevent decision makers from bringing financial considerations among their members. One could also imagine opening bets to the market. Again, the financial incentive would force all participants to bet on the outcome they think will happen, rather than an outcome they say will occur for the sake of forcing a decision. Lastly, the bet need not be as binary as allowing or preventing the merger. One can create a prediction market about the commitments, as I am about to explain.

\subsubsection{Remedies and commitments}

It is not uncommon for antitrust agencies to impose remedies on companies in the context of investigations concerning anticompetitive practices. In the 
case of merger control, companies can "propose" commitments to address the agency's concerns and get their deals through.

These measures are, by definition, forward looking and predictive. While antitrust agencies have long preferred structural commitments (e.g., divestitures) because they entail relatively low monitoring costs, they generally impose behavioral remedies and commitments (e.g., an obligation to grant access to certain infrastructure or IP rights) when an anticompetitive practice has not led to a change in market structure. Companies often perceive such behavioral measures as less constraining than structural ones, although they can be just as coercive.

Both structural and behavioral measures are predictive. For that reason, futarchy can help antitrust agencies achieve their goal: to restore or maintain competition on the market. In practice, futarchy first requires agencies to clarify what measures they want to impose and their objectives. Second, it implies that antitrust agencies submit commitments that are not excessively coercive or unrelated to the harm they are seeking suppress. When these two prerequisites are met, prediction markets could be created for betting on the possible outcomes of various solutions - for example, a price decrease below a certain threshold or a certain number of firms entering the market. Antitrust agencies would then choose the policy that has the highest probability of creating the outcome(s) they are actively seeking to achieve.

\subsubsection{Competition policies}

Futarchy can also be used to design competition policies. By definition, these policies affect a vast number of market players, often in different countries. They have economic implications, but also sociological and philosophical ones. Their design requires complex analyses, which is a substantial reason to bring in the extensive expertise of prediction markets.

Prediction markets could be used to evaluate the opportunity to introduce new guidelines, tools and enforcement priorities. ${ }^{35}$ They could also predict the chances that a decision will be overturned on appeal. Here again, futarchy will require an unambiguous definition of the objective being pursued. Achieving such clarity will present some difficulties, as I will explain. In the meantime, it will also make policies more transparent, which will benefit all market players (and citizens at large). This transparency will prove particularly helpful for preventing policies from being used for strictly politikè (party politics) or

35 Explaining that prediction markets could also be used to draft regulation, see Michael Abramowicz, Predictocracy: Market Mechanisms for Public and Private Decision Making (Yale University Press, 2008): 258. 
personal purposes. ${ }^{36}$ It will increase public awareness concerning these policy choices while leaving agencies in charge of deciding the objectives. ${ }^{37}$

\subsubsection{Challenges}

Up until now, I have focused on futarchy's potential to decentralize antitrust agencies. But futarchy also has challenges that require careful consideration. ${ }^{38}$ Addressing (most of) them will prove crucial to futarchic governance and implementing what I call "futarchic antitrust." I explore them from the least to the most complex.

The first of these challenges relates to prices and, more specifically, their ability to capture all market information. ${ }^{39}$ In fact, some question whether the value of each bet in a prediction market gives a reliable view of the probabilities. But a consensus has emerged in recent decades that there is very little information that the price does not reflect. ${ }^{40}$ This accuracy is visible in real life where prediction markets have proven accurate. ${ }^{41}$ Furthermore, even if prices do not capture all information, they certainly capture more than one can without them.

The second challenge concerns the creation of coalitions to rig the outcome of bets and manipulate markets. ${ }^{42}$ One could indeed create bets on top of prediction markets. Although such a risk cannot be excluded, several observers

36 Thibault Schrepel, “Antitrust Without Romance," NYU Journal of Law \& Liberty 13 (2020).

37 Michael Abramowicz, Predictocracy: Market Mechanisms for Public and Private Decision Making (Yale University Press, 2008): 193. Discussing how prediction markets could constitute "the machinery" of governments, see id. at 283. For a more radical view, see Daniel Larimer, interviewed by Sparkes, 2014 (governments are "going to be losing legitimacy as more open, transparent systems are able to provide that function without having to rely on force").

38 Explaining that the main limits of prediction markets can all be resolved, see Justin Wolfers and Eric Zitzewitz, "Five Open Questions about Prediction Markets," Federal Reserve Bank of San Francisco Working Paper 2006-06 (2006): 23.

39 See, for instance, Justin Wolfers and Eric Zitzewitz, "Prediction Markets," Journal of Economic Perspectives 18 (2004): 107, 112 (discussing the "accuracy of prediction markets").

40 In 1999, see M.A. Hearst, R.D. Hunson and D.G. Stork, "Building intelligent systems one e-citizen at a time," IEEE Intelligent Systems 14, no. 3 (1999): 16 ("On accuracy, decades of research on the efficiency of financial markets have found little price-relevant information that is not reflected in market prices.")

${ }_{41}$ Robert S. Erikson and Christopher Wlezien, "Markets vs. Polls as Election Predictors: An Historical Assessment," Electoral Studies 31, no. 3 (2012). Also, Michael Abramowicz, Predictocracy: Market Mechanisms for Public and Private Decision Making (Yale University Press, 2008): 26.

42 Although, see Robin Hanson et al., "Information Aggregation and Manipulation in an Experimental Market," Journal of Economic Behavior \& Organization 60, no. 4 
have underlined that manipulators actually improve prediction market accuracy by inducing gamblers to be better informed..$^{43}$ On top of that, supervised machine-learning methods have also proven efficient in detecting market manipulation. ${ }^{44}$ Also, let us remember that manipulating prediction markets is very costly, as would-be manipulators lose their money when real-life outcomes do not match their predictions. ${ }^{45}$ In short, futarchic decision making can be influenced by market manipulation, but several factors mitigate this risk.

The third concerns the need to identify easily verifiable outcomes that can be expressed in binary terms ("Boolean values"). Let me break this down. One part relates to quantity: should a prediction market be created to test several objectives (outcomes) instead of just one, the number of participants willing to bet would be most likely reduced. ${ }^{46}$ The other part relates to quality: although one could easily measure a price or GDP increase, some outcomes would be more complex to assess. For example, in a prediction market that questions whether a merger or policy will increase innovation, evaluating the outcome is difficult. To be sure, agencies could choose several metrics for measuring innovation. Still, questions will emerge regarding their capacity to correctly measure the outcome. Also, should the evaluation of these metrics be more subjective, it would create a risk for prediction markets to register incorrect outcomes (e.g., an increase in innovation while innovation has decreased). ${ }^{47}$

(2006): 449 (attempts to manipulate prediction markets generally increase market accuracy by improving liquidity).

43 Robin Hanson and Ryan Oprea, "A Manipulator Can Aid Prediction Market Accuracy,” Economica 76, no. 302 (April, 2009); Patrick Buckley and Fergal O’Brien, "The Effect of Malicious Manipulations on Prediction Market Accuracy," Information Systems Frontiers 19 (2017); Eric Huang and Yoav Shoham "Price Manipulation in Prediction Markets: Analysis and Mitigation," AAMAS (2014).

44 Aihua Li, Liede Wu and Zhidong Liu, "Market Manipulation Detection Based on Classification Methods," Procedia Computer Science 122 (2017).

45 Joyce E. Berg and Thomas A. Rietz, "Market Design, Manipulation, and Accuracy in Political Prediction Markets: Lessons from the Iowa Electronic Markets," Political Science and Politics 47, no. 02 (2014).

46 Also, on the question of the combination of conditional events, see Walter A. Powell et al., Combinatorial Prediction Markets: An Experimental Study in Scalable Uncertainty Management (International Conference on Scalable Uncertainty Management: 2013): 283; Joyce E. Berg and Thomas A. Rietz, "Prediction Markets as Decision Support Systems," Information Systems Frontiers 5 (2003): 79 ("Valuations from 'prediction markets' reveal expectations about the likelihood of events. 'Conditional prediction markets' reveal expectations conditional on other events occurring").

47 Michael Abramowicz, Predictocracy: Market Mechanisms for Public and Private Decision Making (Yale University Press, 2008): 270. 
That being said, prediction markets will force reflection on how to achieve specific goals and measure success. This process will be beneficial in the long run.

Perhaps the most salient barriers to prediction markets are legal ones. Prediction markets are not far from gambling activities (quite heavily) regulated in the United States and Europe. ${ }^{48}$ In 2008, numerous Nobel laureates and economists wrote about "The Promise of Prediction Markets," calling for legal rules to facilitate them. ${ }^{49}$ This has not been done yet.

Against this background, one should discuss creating safe harbors for these markets. ${ }^{50}$ Several fundamental questions will have to be answered along the way to address precisely how to design these comfort zones. For example, one could argue that allowing private gamblers to make money based on prediction markets created by governments requires some safeguards. I am confident that we can, collectively, design such safeguards; the widespread of economic relationships between private and public sectors indicates we have done so in the past. Perhaps the fact that futarchy creates business activities (gambling) that complement or replace state functions raises more critical questions. ${ }^{51}$

Overall, you may have noticed that these criticisms mainly concern prediction markets that are open to everyone. These demand more research. In the meantime, I would recommend starting with small implementations - for example, with the creation of non-binding futarchies whose access is limited to each antitrust agency and using internal blockchain-based tokens. I see this as a great way of attaining the end goal of bringing regulated communities closer to the regulators themselves.

\section{CHAPTER SUMMARY AND BEYOND}

In this chapter, I discussed how cooperation between law and technology could take shape. The first step is to set up a positive agenda that turns their

48 Kenneth J. Arrow et al., "The Promise of Prediction Markets," Science 320, no. 5878 (2008) (asking to free prediction markets of "unnecessary government restrictions").

49 Id.

50 Id. at 877 ("Unfortunately, however, current federal and state laws limiting gambling create significant barriers to the establishment of vibrant, liquid prediction markets in the United States. We believe that regulators should lower these barriers by creating a legal safe harbor for specified types of small-stakes markets, stimulating innovation in both their design and their use.") For instance, the Commodity Futures Trading Commission granted Intrade an exemption to operate in 2005.

51 See Marcella Atzori, "Is the State Still Necessary?" Journal of Governance and Regulation 6, no. 1 (2017): 54 ("Decentralization through distributed blockchains mostly means privatization of public functions, with the transformation of government services and citizens' rights into a new profitable private business"). 
differences into mutual benefits. I argued that creating comfort zones fosters cooperation between lawmakers and industry participants. In parallel, I also argued that it is necessary to shift enforcement activities toward certain malicious practices that threaten the underlying value proposition of blockchain ecosystems. For the time being, agencies should avoid dealing with practices that stem directly from blockchains' core features.

This cooperation between law and technology also requires them to merge on a more practical level. Regulators (here, antitrust agencies) could use blockchains to improve their assessments and monitoring. The technology could also enable antitrust agencies to foster decentralized decision making, blurring the boundaries between law and technology, private entities and governments. In this respect, I have argued that futarchy augmented by blockchain should play a central role because it is efficient and democratic. Whether it concerns merger control, remedies and commitments or antitrust policies, futarchy could play an important role. There are limits to this approach; but instead of waiting for them all to be solved, one could start with carefully designed futarchic governance. This new regulatory environment would foster the integration of blockchain and antitrust. It would simultaneously allow all the other technologies running on blockchain to benefit from this integrated approach. I explore the topic in Chapter 15. 